\title{
BRAF Mutation Is Associated with Improved Local Control of Melanoma Brain Metastases Treated with Gamma Knife Radiosurgery
}

\author{
Ian S. Gallaher', Yoichi Watanabe', Todd E. DeFor ${ }^{2}$, Kathryn E. Dusenbery', \\ Chung K. Lee ${ }^{1}$, Matthew A. Hunt ${ }^{3}$, Hong-Yiou Lin ${ }^{4}$ and Jianling Yuan ${ }^{1 *}$

\begin{abstract}
'Department of Radiation Oncology, University of Minnesota, Minneapolis, MN, USA, ${ }^{2}$ Clinical and Translational Science Institute, University of Minnesota, Minneapolis, MN, USA, ${ }^{3}$ Department of Neurosurgery, University of Minnesota, Minneapolis, MN, USA, ${ }^{4}$ Department of Radiation Oncology, Beaumont Health System, Detroit, MI, USA
\end{abstract}

OPEN ACCESS

Edited by:

Johnny Kao,

Good Samaritan Hospital

Medical Center, USA

Reviewed by:

Joshua Silverman,

New York University Medical

Center, USA

Michael Buckstein,

Icahn School of Medicine

at Mt. Sinai, USA

${ }^{*}$ Correspondence:

Jianling Yuan

yuanm033@umn.edu

Specialty section:

This article was submitted

to Radiation Oncology,

a section of the journal

Frontiers in Oncology

Received: 26 January 2016

Accepted: 15 April 2016

Published: 02 May 2016

Citation:

Gallaher IS, Watanabe Y, DeFor TE,

Dusenbery KE, Lee CK, Hunt MA,

Lin H-Y and Yuan J (2016) BRAF Mutation Is Associated with Improved

Local Control of Melanoma Brain

Metastases Treated with

Gamma Knife Radiosurgery.

Front. Oncol. 6:107.

doi: 10.3389/fonc.2016.00107
Objectives: Evidence has implicated a possible role of tumor mutation status on local control (LC) with radiotherapy. BRAF is a proto-oncogene that is mutated in approximately $50 \%$ of patients with melanoma. We sought to analyze the influence of BRAF status on LC of melanoma brain metastases (MBM) following Gamma Knife radiosurgery (GK).

Methods: Among 125 patients treated with GK for MBM at our institution between 2006 and 2015, we identified 19 patients with 69 evaluable metastases whose BRAF mutation status was known and follow-up imaging was available. LC of individual metastases was compared based on BRAF mutation status using statistical techniques to control for measurements of multiple metastases within each patient. CNS progression was defined as either local failure or development of new lesions.

Results: Of the 69 metastases, BRAF was mutated in 30 and wild-type in 39. With a median follow-up of 30 months for all patients and a median follow-up of 5.5 months for treated lesions, 1-year LC was significantly better among metastases with mutated vs. wild-type $B R A F(69$ vs. $34 \%, R R=0.3,95 \% \mathrm{Cl}=0.1-0.7, p=0.01$ ). BRAF mutation was found to be a significant predictor of $\mathrm{LC}$ after stereotactic radiosurgery (SRS) in both univariate $[\mathrm{RR}=0.3(95 \% \mathrm{Cl} 0.1-0.7, p=0.01)]$ and multivariate $[\mathrm{RR}=0.2(95 \% \mathrm{Cl}$ $0.1-0.7, p=0.01)$ ] analyses. There was also a trend toward improved CNS progression free survival (PFS) at 1 year (26 vs. $0 \%, p=0.06$ ), favoring BRAF-mutated patients.

Conclusion: In this retrospective study, MBM treated with GK had significantly improved LC for patients with BRAF mutation vs. wild-type. Our data suggest that BRAF mutation may sensitize tumors to radiosurgery, and that BRAF wild-type tumors may be more radioresistant.

Keywords: melanoma, brain metastases, BRAF, stereotactic radiosurgery, gamma knife

\section{INTRODUCTION}

Melanoma is the fifth most common malignancy in the US, but the third most common cause of brain metastases. Of the estimated 75,000 people diagnosed annually with melanoma, 7.4-10\% will develop brain metastases (1-3). Among patients presenting with stage IV melanoma, over $40 \%$ have or will develop brain metastases (4). Patients with melanoma brain metastases (MBM) have a 95\% 
chance of dying from their intracranial disease with a median survival time of 6.7 months $(3,5)$. Treatment for MBM includes surgical resection, stereotactic radiosurgery (SRS), whole brain radiation therapy (WBRT), steroids, or a combination of these. In patients with few, asymptomatic metastases, initial treatment with SRS alone is preferred (6-8). However, approximately $30 \%$ of MBM fail locally after SRS (9-11).

Response to SRS for brain metastases depends on several factors. Tumor histology, size, and marginal dose are well-established predictors of local control (LC) (9-13). Emerging evidence suggests that the mutation status within a particular tumor may also influence LC after SRS. Johung et al. analyzed non-small cell lung cancer (NSCLC) patients with brain metastases treated with SRS and found that tumors with EGFR mutations or EML4-ALK translocations rarely recurred in-field, whereas those that lacked such mutations or harbored KRAS mutations were more likely to experience in-field recurrence (14). Other researchers also reported higher response rates to brain radiation among NSCLC patients with mutant EGFR compared to those with wild-type EGFR (15). EGFR and $A L K$ mutations result in constitutive activation of the MAPK pathway, which may confer radiosensitivity (16).

Mutations in the BRAF gene have been reported in approximately $50 \%$ of the patients with melanoma $(17,18)$. The most common mutation, BRAF-V600E, results in substitution of the valine residue with glutamic acid, locking the kinase into a constitutively active conformation. Because BRAF is also an important protein in the MAPK pathway, we hypothesized that BRAF mutation status may influence LC of MBM treated with SRS. We, therefore, identified melanoma patients treated with SRS at our institution and analyzed their outcomes based on $B R A F$ mutation status.

\section{MATERIALS AND METHODS}

\section{Patients}

From a database of patients treated with Gamma Knife (GK) SRS at our institution, we identified patients treated for MBM. Patients were included in this study if their BRAF mutation was known and at least one posttreatment imaging follow-up was available. WBRT, given either before or after SRS, was allowed, however, tumors previously treated with GK or surgical resection were excluded. This study was approved by the institutional review board (IRB code number: 1501M60361).

\section{BRAF Mutation}

$B R A F$ mutation was tested on tissue obtained from biopsy or resection of extra-cranial melanoma. Patients with mutant $B R A F$ were eligible for treatment with BRAF inhibition. BRAF inhibition was given at the discretion of the medical oncologist. The majority of patients were treated with vemurafenib. One patient also received dabrafenib.

\section{Radiation Treatment}

Gamma Knife stereotactic radiosurgery was performed using the Leksell Gamma Knife Model 4C (Elekta AB, Stockholm, Sweden). Radiation dose was selected, with modifications by the prescribing physician, based on tumor size according to the RTOG 9005 trial (19). In general, tumors measuring $<2,2-3$, and $3-4 \mathrm{~cm}$ received 24,18 , and $15 \mathrm{~Gy}$, respectively, with doses generally prescribed to the $50 \%$ isodose line. WBRT was delivered from 6 -MV parallel-opposed beams at $30 \mathrm{~Gy}$ in $10(n=7)$ or $20 \mathrm{~Gy}$ in five fractions $(n=1)$.

\section{Follow-up and Endpoints}

After GK SRS, patients were followed at 3-month intervals with magnetic resonance imaging (MRI) performed at each visit. Patient follow-up duration was defined as time from first GK to last imaging visit or death.

Tumor size was measured in three dimensions on axial, coronal, and sagittal views of pretreatment and follow-up gadoliniumenhanced T1 phase MRI. Tumor volume was estimated with the ellipsoid volume formula. The accuracy of this technique has previously been verified with respect to volume as measured by Leksell Gamma Plan (9). LC of individual metastases was based on modified RECIST criteria. A tumor was defined as locally failed if there was a relative increase in tumor volume on follow-up MRI by $\geq 20 \%$ compared to pretreatment MRI $(9,20)$. Necrosis or hemorrhage was included in volume quantification unless clearly present outside of the tumor. Lesions $(n=3)$ that returned to $<20 \%$ of pretreatment MRI volume on subsequent imaging with only conservative management were considered controlled. The transient volume increase was interpreted as tumor swelling and/ or necrosis rather than treatment failure. CNS progression was defined for patients as either local failure of treated lesions or development of new lesions in the brain.

\section{Statistics}

Patient demographic and treatment characteristics were compared based on BRAF mutation status using the Chi-square test or Fisher's Exact test for categorical variables based on expected cell counts. The general Wilcoxon test was used for continuous variables. Follow-up was measured by reverse Kaplan-Meier curves. CNS progression-free survival (PFS) and overall survival (OS) were calculated from the date of first GK to the date of progression or death, and were estimated with Kaplan-Meier curves. Comparisons were completed with the log-rank-test.

Local control was analyzed for individual metastases using two methods, both of which accounted for assessment of multiple metastases within each patient. First, crude LC at 3 and 6 months was estimated using a non-linear mixed logistic regression. The correlation of clustering of metastases within patients was modeled assuming a normally distributed random variance component (21). All metastases were evaluable for the 3-month assessment. Fifteen metastases were excluded from the 6-month assessment due to lack of imaging. Second, LC was estimated with Kaplan-Meier curves and compared with a Frailty-Cox model accounting for within-cluster correlation by incorporating cluster effects as independent and identically distributed random variables (22). LC was censored for early patient death or loss of follow-up. Although patient numbers were small, we attempted to control for potential confounding of the effect of $B R A F$ mutation on the risk of failure by use of multiple regression in the FrailtyCox model. Additional variables included in the model were use 
of WBRT, marginal dose ( $<22 \mathrm{vs.} \geq 22 \mathrm{~Gy}$ ), and maximum tumor dimension ( $<0.80 \mathrm{vs.} \geq 0.80 \mathrm{~cm}$ ). Treatment volume was excluded from the model due to its high correlation with tumor dimension. All tests were two-sided and considered significant if $p<0.05$. SAS 9.3 (SAS Institute, Cary, NC, USA) and R 3.0.2 (R foundation for Statistical Computing, Vienna, Austria) were used to perform all statistical analyses.

\section{RESULTS}

\section{Patient Characteristics}

We identified 125 patients treated with GK for MBM at our institution since 2006. Of these, 104 patients had either unknown $B R A F$ status (routine testing began in 2011) or inadequate follow-up imaging, and therefore, were excluded, leaving 19 eligible patients. Of these patients, $B R A F$ was mutated in 11 and wild-type in 8 . Characteristics of these two groups of patients were similar with respect to age, gender, presence of extracranial metastases, GPA, number of metastases, use of WBRT and follow-up duration (Table 1). Of the 11 patients with mutant $B R A F$, all but one received a BRAF inhibitor at some point in their treatment course.

\section{Analysis of Individual Metastases}

Among the 19 eligible patients, a total of 69 tumors were treated with GK SRS and had adequate follow-up imaging. Of these, 39 were from patients with wild-type $B R A F$ and 30 were from patients with mutated $B R A F$. Characteristics of these metastases were compared based on BRAF status. Metastases from patients with wild-type $B R A F$ were more likely to have been exposed to WBRT

TABLE 1 | Characteristics of patients by BRAF status.

\begin{tabular}{|c|c|c|c|}
\hline Variable & $\begin{array}{l}B R A F \text { wild-type } \\
(N=8)\end{array}$ & $\begin{array}{c}\text { BRAF-mutated } \\
(N=11)\end{array}$ & $p$-value ${ }^{a}$ \\
\hline Median, age, and range & $58(42-73)$ & $51(32-78)$ & 0.32 \\
\hline Gender: male & $4(50 \%)$ & $5(45 \%)$ & 0.99 \\
\hline $\begin{array}{l}\text { Presence of extra-cranial } \\
\text { metastases }\end{array}$ & $8(100 \%)$ & $9(82 \%)$ & 0.49 \\
\hline GPA & & & 0.30 \\
\hline 1 & $0(0 \%)$ & $2(18 \%)$ & \\
\hline 2 & $3(38 \%)$ & $2(18 \%)$ & \\
\hline 3 & $5(63 \%)$ & $4(36 \%)$ & \\
\hline 4 & $0(0 \%)$ & $3(27 \%)$ & \\
\hline KPS & & & 0.36 \\
\hline$<70$ & $0(0 \%)$ & 1 (9\%) & \\
\hline $70-80$ & $4(50 \%)$ & $3(27 \%)$ & \\
\hline $90-100$ & $4(50 \%)$ & 7 (63\%) & \\
\hline $\begin{array}{l}\text { Number of metastases at } \\
\text { first GK }\end{array}$ & & & 0.99 \\
\hline 1 & $3(38 \%)$ & $5(45 \%)$ & \\
\hline 2 & $2(25 \%)$ & $2(18 \%)$ & \\
\hline$\geq 3$ & 3 (38\%) & 4 (36\%) & \\
\hline Median & $2(1-9)$ & $2(1-50)$ & \\
\hline Use of WBRT: yes & $4(50 \%)$ & $4(36 \%)$ & 0.37 \\
\hline Median F/U (months) & $26(9-26)$ & $32(25-33)$ & 0.87 \\
\hline
\end{tabular}

${ }^{a} p$-value for between-treatment comparisons. Continuous variables were analyzed by general Wilcoxon test. Categorical variables were analyzed by Fisher's exact test. therapy before or after GK (79 vs. 43\%, $p<0.01$ ). Otherwise, there were no significant differences between the two groups (Table 2). The median treatment volume of individual tumors for wild-type vs. mutated $B R A F$ was $2.1 \mathrm{~mL}(0.2-284.8 \mathrm{cc})$ vs. $0.8 \mathrm{~mL}$ (0.1-99.6 $\mathrm{mL}), p=0.45$. The maximum tumor dimension was $1.0 \mathrm{~cm}(0.2-6.2 \mathrm{~cm})$ vs. $0.8 \mathrm{~cm}(0.3-2.9 \mathrm{~cm}), p=0.15$, respectively. Median marginal dose was 22 Gy (12-24 Gy) for both groups, commonly prescribed to the $50 \%$ isodose line. Median followup from GK to last follow-up MRI for individual tumor was 5.5 months (range $=0.7-29.8$ months). Of the 30 metastases with mutated $B R A F$, all but one metastasis were exposed to a BRAF inhibitor at some point in the treatment course. Regarding the timing of BRAF inhibitor treatment in relation to GK SRS, 2 were exposed before GK (by at least 13 days); 10 were exposed before, during, and after; 6 were exposed both before ( $>18$ days) and after ( $>6$ days), but held during GK SRS; and 11 were exposed after ( $>10$ days).

Of the 69 metastases treated with GK, 41 achieved LC (59\%) at a median follow-up of 5.5 months. The 3-and 6-month crude LC for all the treated tumors was 80 and $72 \%$, respectively. When analyzed based on $B R A F$ status, there was a trend for improved crude LC among metastases with mutated $B R A F$ as follow-up time increased. At 3 and 6 months following treatment, crude LC was 72 vs. $90 \%(n=69, p=0.14)$ and 61 vs. $90 \%(n=54$, $p=0.08$ ), respectively (Figure 1A). Since there was loss of information in assessing LC beyond 6 months using mixed models, we also assessed LC with a Frailty model through 1 year, which can incorporate censored patients. With this method, there was a statistically significant improvement in LC among metastases with mutated $B R A F$. At 1 year, LC was 34 vs. $69 \%$ [RR $=0.3$ (95\% CI 0.1-0.7, $p=0.01)$ ] for BRAF wild-type vs. BRAF mutant metastases, respectively (Figure 1B).

\section{Univariate and Multivariate Analysis}

We analyzed the factors affecting LC using univariate analysis (Table 3). In addition to BRAF mutation status being predictive of better LC, a higher marginal dose of $\geq 22$ Gy was also associated with improved LC (67 vs. $27 \%$ at 1 year, $p=0.03$ ). On multiple regression analysis (Table 4), $B R A F$ mutation remained an independent predictor of LC $[\mathrm{RR}=0.2$ (95\% CI 0.1-0.7, $p=0.01)]$. The $p$-value for the effect of marginal dose did not

TABLE 2 | Characteristics of metastases by BRAF status.

\begin{tabular}{|c|c|c|c|}
\hline & $\begin{array}{l}B R A F \text { wild-type } \\
\quad(N=39)\end{array}$ & $\begin{array}{l}\text { BRAF-mutated } \\
\qquad(N=30)\end{array}$ & $p$-value ${ }^{a}$ \\
\hline Use of WBRT & $31(79 \%)$ & $13(43 \%)$ & $<0.01$ \\
\hline GK as initial treatment & $14(36 \%)$ & $3(10 \%)$ & 0.01 \\
\hline $\begin{array}{l}\text { GK as salvage treatment } \\
\text { after WBRT }\end{array}$ & $17(44 \%)$ & 10 (33\%) & 0.39 \\
\hline $\begin{array}{l}\text { Median treatment } \\
\text { volume }(\mathrm{mL})\end{array}$ & $2.1(0.1-284.8)$ & $0.8(0.1-99.6)$ & 0.45 \\
\hline $\begin{array}{l}\text { Median max treatment } \\
\text { dimension }(\mathrm{cm})\end{array}$ & $1.0(0.2-6.2)$ & $0.8(0.3-2.9)$ & 0.15 \\
\hline Median marginal dose (Gy) & $22(15-24)$ & $22(12-24)$ & 0.63 \\
\hline
\end{tabular}

${ }^{a} p$-value for between-treatment comparisons. Continuous variables were analyzed by general Wilcoxon test. Categorical variables were analyzed by the Chi-square test. 
A
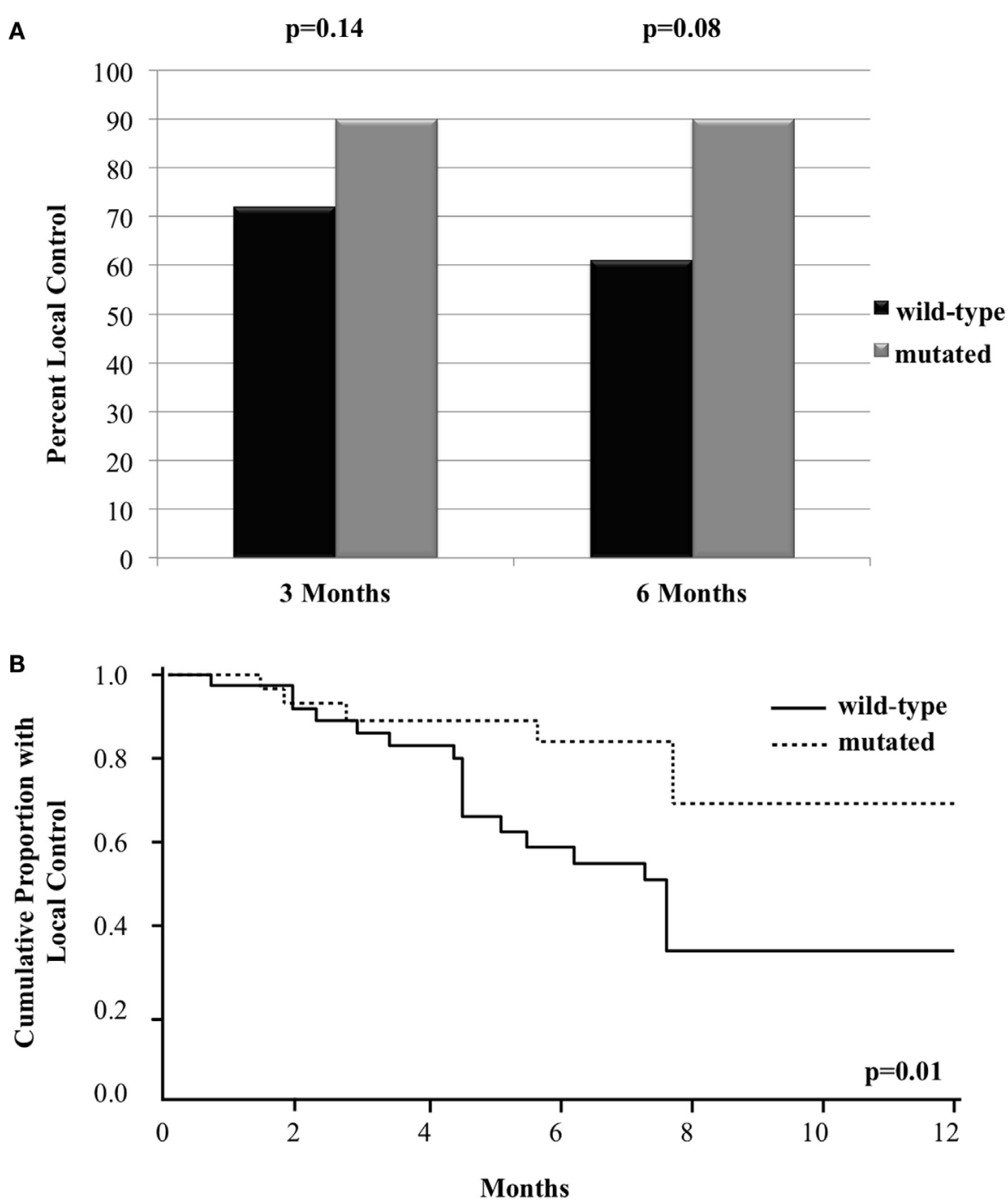

FIGURE 1 | Local control of metastases in patients with mutated compared to wild-type BRAF with (A) bar graph of crude local control at 3 and 6 months and (B) Kaplan-Meier curve of overall local control through 12 months.

reach significance. LC was not influenced by max tumor dimension or the use of WBRT. Because all but one metastasis with mutated $B R A F$ were exposed to a BRAF inhibitor, analysis of LC with regard to exposure of targeted therapy was not conducted. However, we did analyze the timing of BRAF inhibitor exposure relative to GK SRS and found no correlation with LC among the 29 metastases that received targeted therapy (Table 5).

\section{Patient Outcomes}

At a median follow-up of 30 months, the median OS for the entire group of patients was 21 months. Survival was not different based on BRAF mutation status. The median OS was 21 months for patients with wild-type or mutated $B R A F$, with a 2-year survival of $38 \%$ (95\% CI $6-72 \%)$ vs. $45 \%$ (95\% CI $17-71 \%)$, respectively $(p=0.92$, Figure 2A). There was a trend toward improved CNS PFS among patients with BRAF mutation [26\% (95\% CI 4-56\%) vs. $0 \%$ at 1 year, $p=0.06$, Figure $2 B$ ]. The incidence of CNS progression for wild-type vs. mutated $B R A F$ was $87 \%$ (95\% CI $58-99 \%)$ vs. $39 \%$ (95\% CI 16-73\%), respectively at 3 months $(p=0.11)$ and 100 vs. $74 \%$, respectively, at both 6 and 12 months $(p=0.06)$. The improved CNS PFS seen among the BRAFmutated patients appears to be primarily attributed to a better LC of GK-treated metastases. Of the 8 patients with wild-type $B R A F$, all patients failed at at least 1 treated local sites (2 local only, 6 local and distant), whereas of the 11 patients with mutated $B R A F$, only 5 patients experienced local failure (all of whom also had distant failure).

\section{DISCUSSION}

In this retrospective study, we examined the LC of MBM treated with GK SRS with respect to $B R A F$ mutation status. We found 
TABLE 3 | Univariate analysis of local control for metastases treated with GK SRS.

\begin{tabular}{|c|c|c|c|c|c|c|}
\hline Factor & $N$ & \# events & $\begin{array}{l}\text { Local control } \\
\text { at } 1 \text { year }(\%)\end{array}$ & $\begin{array}{l}\text { Median months } \\
\text { to failure }\end{array}$ & $\begin{array}{l}\text { Relative risk of } \\
\text { failure }(95 \% \mathrm{Cl})\end{array}$ & $p$-value \\
\hline Overall & 69 & 26 & 49 & 7.7 & & \\
\hline BRAF & & & & & & 0.01 \\
\hline Wild-type & 39 & 19 & 34 & 4.5 & 1.0 & \\
\hline Mutated & 30 & 7 & 69 & 5.6 & $0.3(0.1-0.7)$ & \\
\hline WBRT & & & & & & 0.19 \\
\hline No & 25 & 7 & 65 & 2.7 & 1.0 & \\
\hline Yes & 44 & 19 & 40 & 6.2 & $1.9(0.7-5.2)$ & \\
\hline Treatment volume (ml) & & & & & & 0.83 \\
\hline$<1.0$ & 34 & 14 & 52 & 7.4 & 1.0 & \\
\hline$\geq 1.0$ & 35 & 12 & 44 & 4.5 & $1.1(0.5-2.5)$ & \\
\hline Max tumor dimension (cm) & & & & & & 0.46 \\
\hline$<0.80$ & 29 & 16 & 55 & 7.6 & 1.0 & \\
\hline$\geq 0.80$ & 40 & 10 & 45 & 4.5 & $1.4(0.6-3.2)$ & \\
\hline Marginal dose & & & & & & 0.03 \\
\hline$<22$ Gy & 30 & 16 & 27 & 5.3 & 1.0 & \\
\hline$\geq 22$ Gy & 39 & 10 & 67 & 3.9 & $0.4(0.2-0.9)$ & \\
\hline
\end{tabular}

TABLE 4 | Multiple regression analysis of local control for metastases treated with GK SRS.

\begin{tabular}{|c|c|c|c|c|}
\hline Factor $^{a}$ & $N$ & \# events & $\begin{array}{l}\text { Relative risk of } \\
\text { failure }(95 \% \mathrm{Cl})\end{array}$ & $p$-value \\
\hline$B R A F$ & & & 0.01 & 0.01 \\
\hline Wild-type & 39 & 19 & 1.0 & \\
\hline Mutated & 30 & 7 & $0.2(0.1-0.7)$ & \\
\hline WBRT & & & & 0.92 \\
\hline No & 25 & 7 & 1.0 & \\
\hline Yes & 44 & 19 & $0.9(0.3-3.0)$ & \\
\hline Marginal dose & & & & 0.07 \\
\hline$<22$ Gy & 30 & 16 & 1.0 & \\
\hline$\geq 22$ Gy & 39 & 10 & $0.4(0.2-1.1)$ & \\
\hline Max tumor dimension & & & & 0.89 \\
\hline$<0.80 \mathrm{~cm}$ & 29 & 16 & 1.0 & \\
\hline$\geq 0.80 \mathrm{~cm}$ & 40 & 10 & $0.9(0.3-2.5)$ & \\
\hline
\end{tabular}

${ }^{a}$ Tumor volume not included due to high correlation with tumor dimension.

a significantly improved LC among metastases carrying $B R A F$ mutation compared to those with wild-type $B R A F$. Among brain metastases harboring mutated $B R A F, 1$-year LC was $69 \%$, whereas those with wild-type BRAF have an inferior LC of $34 \%(p=0.01)$. There was also a trend toward improved CNS PFS among patients with mutated $B R A F$, which appears to be primarily due to better LC of GK-treated metastases.

Our finding that the presence of $B R A F$ mutation is associated with an improved LC raises the possibility that $B R A F$ mutation may directly influence radiosensitivity when these tumors are treated with SRS. This is in keeping with recent observation made in NSCLC, in which patients with EGFR mutations or EML4-ALK translocations experience a significantly better infield control compared to those without such mutations or those harboring KRAS mutations instead $(14,15)$. These mutations are similar to $B R A F$ mutation in that they all result in constitutive activation of the MAPK pathway (16). The association could suggest a common mechanism such as increased proliferative rate and thus increased susceptibility to radiation therapy.

To our knowledge, there is only one published study that also addressed the influence of $B R A F$ mutation status on LC following SRS for MBM (23). The study included 52 melanoma patients with 185 treated brain metastases. Unlike our study, a difference in LC with regard to mutation status was not found. The 1-year LC was $67.1 \%$ among MBM in patients with wild-type $B R A F$ and $70.0 \%$ for $M B M$ in patients with $B R A F$ mutation. Instead, they found that the use of BRAF inhibitor was significantly associated with 1 -year LC (85.0\% with vs. $51.5 \%$ without) (23). All but one patient with mutant $B R A F$ in our study received a BRAF inhibitor at some point during their treatment course. It is possible that the improved LC observed in our patients is entirely conferred by the use of a BRAF inhibitor.

Several other studies reported the use of BRAF inhibitors in the setting of brain radiation therapy. In a small series by Narayana et al., 12 patients with $B R A F$ mutations were treated with either SRS or WBRT prior to or along with vemurafenib. A $75 \%$ radiographic response was observed among index lesions, including a $48 \%$ complete response and a $27 \%$ partial response (24). In another study, 24 patients with 80 metastatic brain lesions were treated with SRS while on vemurafenib. LC at 6 months and 1 year was 92 and $75 \%$, respectively and was felt to be better than reported control rates among melanoma patients treated with SRS alone. The authors suggested that there may be a synergistic effect between BRAF inhibitors and SRS (25). However, neither study compared the outcome directly to $B R A F$-mutated patients not treated with an inhibitor. Therefore, the possibility still exists that $B R A F$ mutation itself may impact radiosensitivity directly.

It is not clear whether or how BRAF inhibition acts synergistically with SRS. In the aforementioned study by Ly et al., the majority of lesions were not treated with a BRAF inhibitor within a 30-day period before or after SRS. Among the remaining lesions, 
TABLE 5 | Univariate analysis of timing of BRAF inhibitor on local control for metastases treated with GK SRS.

\begin{tabular}{lcccc}
\hline Timing of BRAF inhibitor use & N & \# events & $\begin{array}{c}\text { Local control } \\
\text { at 1 year (\%) }\end{array}$ & $\begin{array}{c}\text { Median months } \\
\text { to failure } \\
\text { failure (95\% Cl) }\end{array}$ \\
\hline After GK SRS & 11 & 4 & 64 & 7.7 \\
Before and after GK SRS & 16 & 2 & 87 & 1.0 \\
Before GK SRS & 2 & 1 & 50 & $2.0(0.2-17.8)$ \\
\end{tabular}

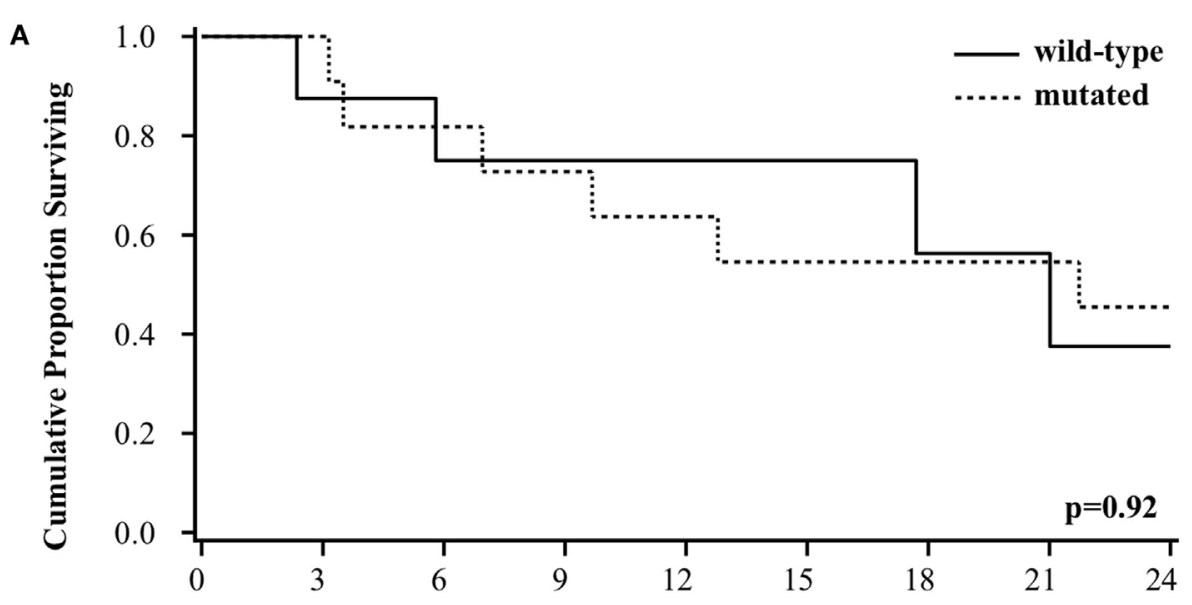

Months

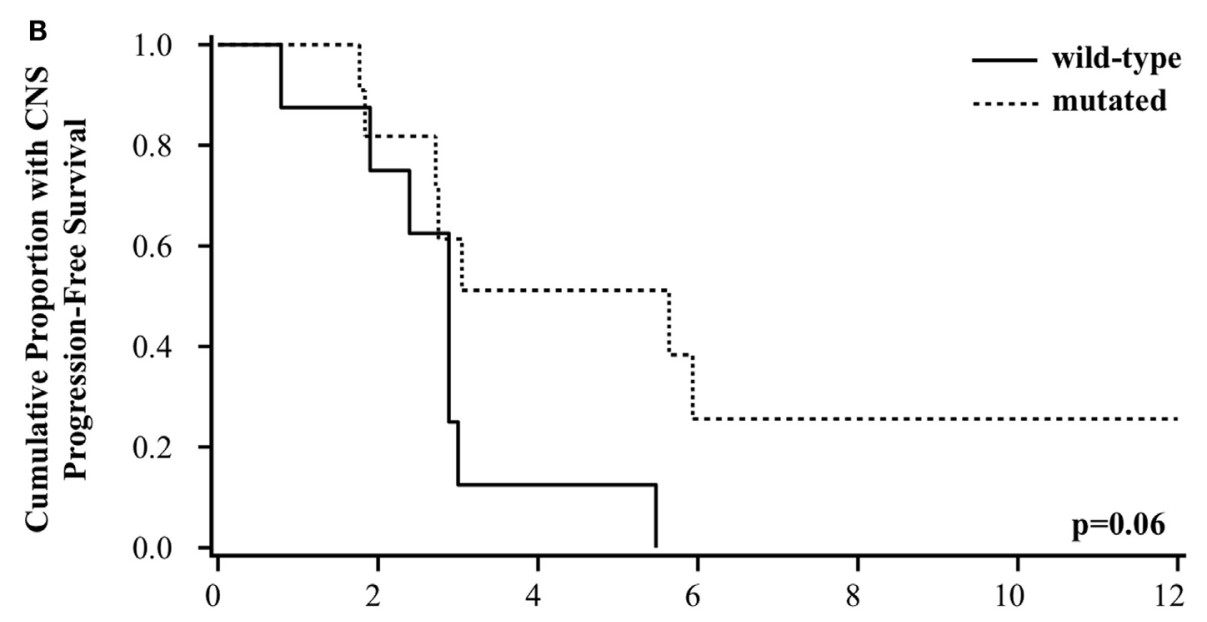

Months

FIGURE 2 | Kaplan-Meier curve of (A) overall survival and (B) CNS progression-free survival among patients based on BRAF mutation status.

a washout period of 7 days (range 1-20 days) was instituted (23). However, the median elimination half-life is only $50 \mathrm{~h}$ for vemurafenib, and even shorter for dabrafenib $(5 \mathrm{~h})(26,27)$. It is therefore difficult to account for the improved LC observed using a traditional radiosensitization model in which the drug is expected to be present at the time of radiation, as shown in vitro for melanoma cell lines $(28,29)$. We also analyzed the timing of BRAF inhibitor exposure on LC with SRS, and we did not observe any correlation. However, our sample size was small with only 29 metastases receiving targeted therapy.

Another unresolved issue is in regard to the safety of the concurrent use of a BRAF inhibitor with SRS. An increased rate and severity of radiation dermatitis has been observed when BRAF inhibition is used concomitantly with conventionally fractionated radiotherapy. This has lead many investigators to transiently hold drug therapy for patients undergoing SRS. 
However, the necessity and appropriate duration of the "washout" period has not been established. In the study by Ly et al., the median washout period ranged from 1 to 20 days with a median of 7 days (23). In the study by Ahmed et al., patients were told to hold the drug for 2-3 days before and after SRS treatment (25). Yet in another study that primarily assessed the safety of concurrent treatment, 20 patients had no interruption of BRAF inhibitor while undergoing SRS. No cases of radiationinduced necrosis and no scalp radiation dermatitis occurred. A relatively small rate of edema and hemorrhage was detected, which is not unexpected following SRS for MBM (30). This is in contrast to the study by Ly et al. that reported a significantly increased intratumoral hemorrhage risk among patients treated with a BRAF inhibitor. Given the 1-year freedom from intratumoral hemorrhage rate of only $39.3 \%$, the authors recommend discontinuation of BRAF inhibitors for 1-2 weeks both before and after treatment, provided systemic disease is controlled (23). We did not observe an unexpectedly high rate of posttreatment intratumoral hemorrhage among the 10 patients treated concurrently with a BRAF inhibitor. The presence of hemorrhage on MRI was not always commented upon by radiologist, and therefore, our number could be underreported. While these issues are being sorted out, it remains an attractive hypothesis that if $B R A F$ mutation itself is associated with an enhanced radiosensitivity to $S R S$, then the use of a lower marginal dose may decrease the risk of tumor hemorrhage without compromising LC in this group of patients. This would be particularly helpful when there is concern for systemic disease progression if the BRAF inhibitor is held.

During final manuscript preparation, we came across a study similar to ours presented by Kotecha and colleagues in abstract form (31). They reported 25 patients with MBM treated with SRS. BRAF-mutated patients had a significantly improved OS and PFS compared to BRAF wild-type patients. Of the $48 \mathrm{MBM}$ with recurrence information available, they found a higher rate of in-field failure among $B R A F$ wild-type metastases $(8 / 20)$ vs. those that are $B R A F$-mutated $(4 / 28 ; p=0.04)$. Their results, therefore, corroborate our finding, also suggesting the potential impact of $B R A F$ status on outcome after SRS.

Our study has several limitations. Our sample size is small with only 69 eligible metastases in 19 eligible patients. Despite this

\section{REFERENCES}

1. Siegel RL, Miller KD, Jemal A. Cancer statistics, 2015. CA Cancer J Clin (2015) 65:5-29. doi:10.3322/caac. 21254

2. Schouten LJ, Rutten J, Huveneers HA, Twijnstra A. Incidence of brain metastases in a cohort of patients with carcinoma of the breast, colon, kidney, and lung and melanoma. Cancer (2002) 94:2698-705. doi:10.1002/ cncr.10541

3. Sampson JH, Carter JH Jr, Friedman AH, Seigler HF. Demographics, prognosis, and therapy in 702 patients with brain metastases from malignant melanoma. J Neurosurg (1998) 88:11-20. doi:10.3171/jns.1998.88.1.0011

4. Davies MA, Liu P, McIntyre S, Kim KB, Papadopoulos N, Hwu WJ, et al. Prognostic factors for survival in melanoma patients with brain metastases. Cancer (2011) 117:1687-96. doi:10.1002/cncr.25634

5. Sperduto PW, Kased N, Roberge D, Xu Z, Shanley R, Luo X, et al. Summary report on the graded prognostic assessment: an accurate and facile size, there were trends that could reach significance with larger sample sizes. Another limitation is the retrospective nature of the study, which inherently does not allow for control of unknown variables between the two groups. It is encouraging that Kotecha et al. recently reported similar findings. Nevertheless, confirmatory studies from other institutions and from larger databases would be required to fully assess the impact of BRAF on SRS outcomes. Finally, the mutation status of BRAF obtained from the primary site or a more accessible metastatic site was assumed for the intracranial tumors. Metastatic tumors may change molecular subtype during disease course as has been shown for breast cancer (32).

\section{CONCLUSION}

In this retrospective study, we analyzed the outcome of MBM treated with GK SRS and found that lesions with BRAF mutation appear to have an improved LC compared to those with wild-type BRAF. It is unclear whether this is caused by inherent radiosensitivity associated with the mutation, or due to the use of a BRAF inhibitor. Further studies will be required to fully characterize the role of BRAF mutation in LC of brain metastases treated with SRS.

\section{AUTHOR CONTRIBUTIONS}

IG and JY designed the research, collected, analyzed, interpreted the data, and wrote the manuscript. YW, MH, KD, CL, and $\mathrm{H}$-YL designed the research, collected the data, and revised the manuscript. TD (statistician) analyzed and interpreted the data and drafted portions of the manuscript. All authors are accountable for all aspects of work in ensuring that questions related to accuracy or integrity of work are appropriately investigated and resolved.

\section{FUNDING}

There are no funding sources to report apart from departmental academic allowance. diagnosis-specific tool to estimate survival for patients with brain metastases. J Clin Oncol (2012) 30:419-25. doi:10.1200/JCO.2011.38.0527

6. Chang EL, Wefel JS, Hess KR, Allen PK, Lang FF, Kornguth DG, et al. Neurocognition in patients with brain metastases treated with radiosurgery or radiosurgery plus whole-brain irradiation: a randomised controlled trial. Lancet Oncol (2009) 10:1037-44. doi:10.1016/S1470-2045(09)70263-3

7. Soffietti R, Kocher M, Abacioglu UM, Villa S, Fauchon F, Baumert BG, et al. A European organisation for research and treatment of cancer phase III trial of adjuvant whole-brain radiotherapy versus observation in patients with one to three brain metastases from solid tumors after surgical resection or radiosurgery: quality-of-life results. J Clin Oncol (2013) 31:65-72. doi:10.1200/ JCO.2011.41.0639

8. NCCN. Clinical Practice Guidelines in Oncology: Central Nervous System Cancers. V.2 [Internet]. (2014). Available from: www.nccn.org

9. Lin H, Watanabe Y, Cho LC, Yuan J, Hunt MA, Sperduto PW, et al. Gamma knife stereotactic radiosurgery for renal cell carcinoma and melanoma 
brain metastases - comparison of dose response. J Radiosurg SBRT (2013) 2:193-207.

10. Lo SS, Clarke JW, Grecula JC, McGregor JM, Mayr NA, Cavaliere R, et al. Stereotactic radiosurgery alone for patients with 1-4 radioresistant brain metastases. Med Oncol (2011) 28:439-44. doi:10.1007/s12032-010-9670-5

11. Powell JW, Chung CT, Shah HR, Canute GW, Hodge CJ, Bassano DA, et al. Gamma Knife surgery in the management of radioresistant brain metastases in high-risk patients with melanoma, renal cell carcinoma, and sarcoma. J Neurosurg (2008) 109(Suppl):122-8. doi:10.3171/JNS/2008/109/12/S19

12. Liew DN, Kano H, Kondziolka D, Mathieu D, Niranjan A, Flickinger JC, et al. Outcome predictors of gamma knife surgery for melanoma brain metastases: clinical article. J Neurosurg (2011) 114:769-79. doi:10.3171/2010.5.JNS1014

13. Molenaar R, Wiggenraad R, Verbeek-de Kanter A, Walchenbach R, Vecht C. Relationship between volume, dose and local control in stereotactic radiosurgery of brain metastasis. Br J Neurosurg (2009) 23:170-8. doi:10.1080/02688690902755613

14. Johung KL, Yao X, Li F, Yu JB, Gettinger SN, Goldberg S, et al. A clinical model for identifying radiosensitive tumor genotypes in non-small cell lung cancer. Clin Cancer Res (2013) 19:5523-32. doi:10.1158/1078-0432. CCR-13-0836

15. Lee HL, Chung TS, Ting LL, Tsai JT, Chen SW, Chiou JF, et al. EGFR mutations are associated with favorable intracranial response and progression-free survival following brain irradiation in non-small cell lung cancer patients with brain metastases. Radiat Oncol (2012) 7:181. doi:10.1186/1748-717X-7-181

16. Downward J. Targeting RAS signalling pathways in cancer therapy. Nat Rev Cancer (2003) 3:11-22. doi:10.1038/nrc969

17. Long GV, Menzies AM, Nagrial AM, Haydu LE, Hamilton AL, Mann GJ, et al. Prognostic and clinicopathologic associations of oncogenic BRAF in metastatic melanoma. JClin Oncol (2011) 29:1239-46. doi:10.1200/ JCO.2010.32.4327

18. Davies H, Bignell GR, Cox C, Stephens P, Edkins S, Clegg S, et al. Mutations of the BRAF gene in human cancer. Nature (2002) 417:949-54. doi:10.1038/ nature00766

19. Shaw E, Scott C, Souhami L, Dinapoli R, Kline R, Loeffler J, et al. Single dose radiosurgical treatment of recurrent previously irradiated primary brain tumors and brain metastases: final report of RTOG protocol 90-05. Int J Radiat Oncol Biol Phys (2000) 47:291-8. doi:10.1016/S0360-3016(99)00507-6

20. Eisenhauer E, Therasse P, Bogaerts J, Schwartz L, Sargent D, Ford R, et al. New response evaluation criteria in solid tumours: revised RECIST guideline (version 1.1). Eur JCancer (2009) 45:228-47. doi:10.1016/ j.ejca.2008.10.026

21. McMahon JM, Pouget ER, Tortu S. A guide for multilevel modeling of dyadic data with binary outcomes using SAS PROC NLMIXED. Comput Stat Data Anal (2006) 50:3663-80. doi:10.1016/j.csda.2005.08.008

22. Ripatti S, Palmgren J. Estimation of multivariate frailty models using penalized partial likelihood. Biometrics (2000) 56:1016-22. doi:10.1111/ j.0006-341X.2000.01016.x

23. Ly D, Bagshaw HP, Anker CJ, Tward JD, Grossmann KF, Jensen RL, et al. Local control after stereotactic radiosurgery for brain metastases in patients with melanoma with and without BRAF mutation and treatment. J Neurosurg (2015) 123:395-401. doi:10.3171/2014.9.JNS141425

24. Narayana A, Mathew M, Tam M, Kannan R, Madden KM, Golfinos JG, et al. Vemurafenib and radiation therapy in melanoma brain metastases. J Neurooncol (2013) 113:411-6. doi:10.1007/s11060-013-1127-1

25. Ahmed KA, Freilich JM, Sloot S, Figura N, Gibney GT, Weber JS, et al. LINACbased stereotactic radiosurgery to the brain with concurrent vemurafenib for melanoma metastases. J Neurooncol (2015) 122:121-6. doi:10.1007/ s11060-014-1685-x

26. Flaherty KT, Puzanov I, Kim KB, Ribas A, McArthur GA, Sosman JA, et al. Inhibition of mutated, activated BRAF in metastatic melanoma. $N$ Engl J Med (2010) 363:809-19. doi:10.1056/NEJMoa1002011

27. Falchook GS, Long GV, Kurzrock R, Kim KB, Arkenau TH, Brown MP, et al. Dabrafenib in patients with melanoma, untreated brain metastases, and other solid tumours: a phase 1 dose-escalation trial. Lancet (2012) 379:1893-901. doi:10.1016/S0140-6736(12)60398-5

28. Sambade MJ, Peters EC, Thomas NE, Kaufmann WK, Kimple RJ, Shields JM. Melanoma cells show a heterogeneous range of sensitivity to ionizing radiation and are radiosensitized by inhibition of B-RAF with PLX-4032. Radiother Oncol (2011) 98:394-9. doi:10.1016/j. radonc.2010.12.017

29. Dasgupta T, Yang X, Hashizume R, Olow A, Kolkowitz I, Weiss W, et al. Survival advantage with radiation combined with a selective BRAFV600E inhibitor in an orthotopic, intracranial model of BRAFV600E-mutated highgrade gliomas. Int J Radiat Oncol Biol Phys (2012) 84:S125. doi:10.1016/j. ijrobp.2012.07.125

30. Gaudy-Marqueste C, Carron R, Delsanti C, Loundou A, Monestier S, Archier E, et al. On demand gamma-knife strategy can be safely combined with BRAF inhibitors for the treatment of melanoma brain metastases. Ann Oncol (2014) 25:2086-91. doi:10.1093/annonc/mdu266

31. Kotecha R, Venur VA, Murphy ES, Yu JS, Chao ST, Suh JH, et al. Impact of BRAF mutation on outcome following stereotactic radiosurgery in melanoma brain metastases. Int J Radiat Oncol Biol Phys (2015) 93:S58. doi:10.1016/j. ijrobp.2015.07.139

32. Holdaway I, Bowditch J. Variation in receptor status between primary and metastatic breast cancer. Cancer (1983) 52:479-85. doi:10.1002/10970142(19830801)52:3<479::AID-CNCR2820520317>3.0.CO;2-O

Conflict of Interest Statement: The authors declare that the research was conducted in the absence of any commercial or financial relationships that could be construed as a potential conflict of interest.

Copyright $\odot 2016$ Gallaher, Watanabe, DeFor, Dusenbery, Lee, Hunt, Lin and Yuan. This is an open-access article distributed under the terms of the Creative Commons Attribution License (CC BY). The use, distribution or reproduction in other forums is permitted, provided the original author(s) or licensor are credited and that the original publication in this journal is cited, in accordance with accepted academic practice. No use, distribution or reproduction is permitted which does not comply with these terms. 